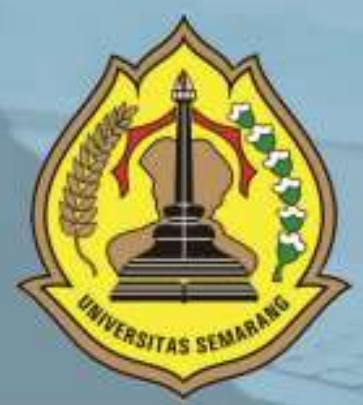

PENGARUH WORK FAMILY CONFLICT, STRES KERJA DAN KEPEMIMPINAN TERHADAP TURNOVER INTENTION KARYAWAN (STUDI PADA SELURUH KARYAWAN BAGIAN PLANNING PRODUCTION AND INVENTORY CONTROL PT. PARKLAND WORLD INDONESIA JEPARA

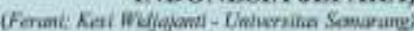

STUDI SOFT SKILL LULUSAN PENDIDIKAN KEJURUAN DI TEMPAT KERJA

Whort-Chiversikio Semorang

ANALISIS IINGKUNGAN INTERNAL DAN EKSTERNAL, PADA UKM PREMIUM PLUS LAUNDRY CABANG MULAWARMAN SEMARANG

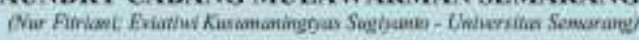

FAKTOR-FAKTOR YANG MEMPENGARUHI PERTIMBANGAN TINGKAT MATERIALITAS AUDIT

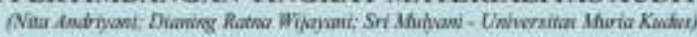

MANAJEMEN LABA DAN FAKTOR-FAKTOR YANG MEMPENGARUHINYA (STUDI EMPIRIS PADA PERUSAHAN MANUFAKTUR DI BEI)

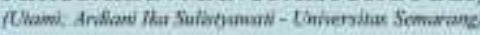

PENDAPATAN ASLI DAERAH, DANA PERIMBANGAN, DAN SISA LEBIH PEMBIAYAAN ANGGARAN TERHADAP PENGALOKASIAN BELANJA MODAL: STUDI PADA KABUPATEN/KOTA DI PROVINSI JAWA TENGAH

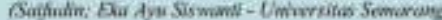

PERSEPSI PENGGUNA JASA TRANS JATENG TERHADAP KUALITAS PELAYANAN ANGKUTAN AGLOMERASI PERKOTAAN TRANS

JATENG

(Studi Kasus Trans Jateng Koridor I Semarang (Tawang) - Bawen)

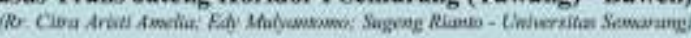

WORTHLESSNESS IS A POWER: MENGAPA ORANG BERSEDIA MENARUH UANG DI APLIKASI GO-PAY

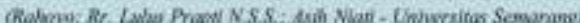

ANALISIS PENGARUH KUALITAS PRODUK, PERSEPSI HARGA, DAN PROMOSI TERHADAP KEPUTUSAN PEMBEIIAN WELLBLUE AL KALINE WATER PITCHER

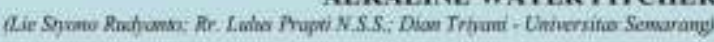

STRATEGI PEMASARAN UNTUK MENINGKATKAN VOLUME PENJUALAN (STUDI KASUS PADA SHOFA CATERING)

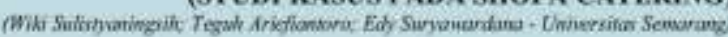

PENGARUH CITRA MEREK, PERSEPSI HARGA, DAN KUALITAS PRODUK TERHADAP KEPUTUSAN PEMBELIAN SEPATU OLAH RAGA MEREK ADIDAS

(Studi di Kota Semarang)

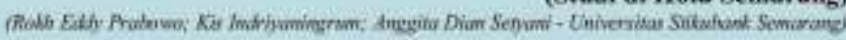

PENGARUH KEMUDAHAN TERHADAP KEPUTUSAN MENGGUNAKAN E-BANKING PADA BNI 46 KC KARANGAYU SEMARANG DENGAN MINAT NASABAH DAN KEPERCAYAAN SEBAGAI VARIABEL. MEDIASI

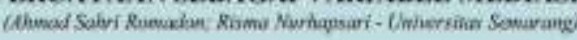

PENELITLAN KEBERLANGSUNGAN USAHA ARDANI INDONESIA SEBAGAI UMKM BERBASIS INDUSTRI KREATIF

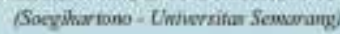

STRATEGI PELAYANAN BUS RAPID TRANSIT (BRT) TRANS SEMARANG

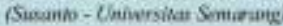

ANALISIS PENGARUH KEPEMIMPINAN, STRES KERJA, DAN LINGKUNGAN KERJA TERHADAP KINERJA KARYAWAN BAGIAN PRODUKSI SEWING PT. SAMWON BUSANA INDONESIA SEMARANG

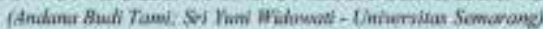




\section{DESKRIPSI}

Majalah IImiah Solusi Mengkaji

Masalah-Masalah Sosial,

Ekonomi dan Bisnis

\section{KETERANGAN TERBIT}

Terbit Pertama Kali Juli 2002

dan SelanjutnyaTerbit Tiga Bulan

Sekali (Januari, April, Juli dan

Oktober)

\section{PENERBIT}

Fakultas Ekonomi USM

\section{ALAMAT PENERBIT}

JL. Soekarno Hatta Semarang

Telp. 024-6702757 Fax. 024-6702272

\section{PENGELOLA}

Editor in Chief : Yohanes Suhardjo, SE, M.Si., Ak, CA Vice Editor Chief : Sugeng Rianto, SE, MM

Managing Editor: Edy Suryawardana, SE, MM

Secretary of Managing Editor : Asih Niati, SE, MM

Administration \& Circulation :

Citra Rizkiana, SE, MM

Layout \& Typesetting : M Burhan Hanif S.Kom, M.Kom

Board of Editors:

1. Prof. Dr. Ir. Kesi Widjajanti, SE, MM (USM)

2. Prof. Drs. Mohammad Nasir, Msi, Ph.D, AK. (USM)

3. Prof. Supramono SE, MBA, DBA (UKSW)

4. Prof. Drs. H. Imam Ghozali, M.Com, Akt, PhD (UNDIP)

5. Prof. Dr. Agus Suroso, MS (UNSOED)

6. Prof. Dr. Widodo, SE, M.Si (UNISSULA)

7. Prof. Dr. Dra. Sulastri, ME, M.Kom (UNSRI)

8. Dr. Ardiani Ika S, SE, MM, Ak, CA, CPA (USM)

\section{KATA PENGANTAR}

Sungguh merupakan kebahagiaan tersendiri bagi kami, takala kami dapat hadir rutin setiap tiga bulan sekali untuk saling bertukar pikiran mengenai hal-hal baru dibidang sosial, ekonomi dan bisnis.

Pada kesempatan ini penerbit menyampaikan terima kasih kepada semua pihak yang telah mengirimkan artikel-artikelnya. Penerbit akan membuka kesempatan seluas-luasnya bagi seluruh kalangan akademisi maupun praktisi baik dari dalam maupun luar Universitas Semarang untuk mempublikasikan karya ilmiahnya.

Penerbitan majalah ilmiah "SOLUSI" kali ini menghadirkan 15 (Lima Belas) artikel yang kami anggap layak untuk diterbitkan, dengan harapan dapat menjadi tambahan referensi bagi para pembaca dan menjadi sumbangan pengembangan persemaian khasanah pengetahuan dibidang sosial, ekonomi dan bisnis.

Akhir kata semoga majalah ilmiah "SOLUSI" dapat memberi manfaat yang sebesar-besarnya.

Hormat Kami 


\section{DAFTAR ISI}

PENGARUH WORK FAMILY CONFLICT, STRES KERJA DAN KEPEMIMPINAN TERHADAP TURNOVER INTENTION KARYAWAN (STUDI PADA SELURUH KARYAWAN BAGIAN PLANNING PRODUCTION AND INVENTORY CONTROL PT. PARKLAND WORLD INDONESIA JEPARA)

(Ferani; Kesi Widjajanti - Universitas Semarang)

STUDI SOFT SKILL LULUSAN PENDIDIKAN KEJURUAN DI TEMPAT KERJA

(Albert - Universitas Semarang)...

ANALISIS LINGKUNGAN INTERNAL DAN EKSTERNAL PADA UKM PREMIUM PLUS

LAUNDRY CABANG MULAWARMAN SEMARANG

(Nur Fitriani; Eviatiwi Kusumaningtyas Sugiyanto - Universitas Semarang)

FAKTOR-FAKTOR YANG MEMPENGARUHI PERTIMBANGAN TINGKAT

MATERIALITAS AUDIT

(Nita Andriyani; Dianing Ratna Wijayani; Sri Mulyani - Universitas Muria Kudus).

MANAJEMEN LABA DAN FAKTOR-FAKTOR YANG MEMPENGARUHINYA

(STUDI EMPIRIS PADA PERUSAHAN MANUFAKTUR DI BEI)

(Utami; Ardiani Ika Sulistyawati - Universitas Semarang)

PENDAPATAN ASLI DAERAH, DANA PERIMBANGAN, DAN SISA LEBIH PEMBIAYAAN ANGGARAN TERHADAP PENGALOKASIAN BELANJA MODAL: STUDI PADA

KABUPATEN/KOTA DI PROVINSI JAWA TENGAH

(Saifudin; Eka Ayu Siswanti - Universitas Semarang).

PERSEPSI PENGGUNA JASA TRANS JATENG TERHADAP KUALITAS PELAYANAN ANGKUTAN AGLOMERASI PERKOTAAN TRANS JATENG

(Studi Kasus Trans Jateng Koridor I Semarang (Tawang) - Bawen)

(Rr. Citra Aristi Amelia; Edy Mulyantomo; Sugeng Rianto - Universitas Semarang)

WORTHLESSNESS IS A POWER: MENGAPA ORANG BERSEDIA MENARUH UANG DI APLIKASI GO-PAY

(Rahoyo; Rr. Lulus Prapti N.S.S.; Asih Niati - Universitas Semarang).

ANALISIS PENGARUH KUALITAS PRODUK, PERSEPSI HARGA, DAN PROMOSI TERHADAP KEPUTUSAN PEMBELIAN WELLBLUE ALKALINE WATER PITCHER

STRATEGI PEMASARAN UNTUK MENINGKATKAN VOLUME PENJUALAN (STUDI KASUS PADA SHOFA CATERING)

(Wiki Sulistyaningsih; Teguh Ariefiantoro; Edy Suryawardana - Universitas Semarang)

PENGARUH CITRA MEREK, PERSEPSI HARGA, DAN KUALITAS PRODUK TERHADAP KEPUTUSAN PEMBELIAN SEPATU OLAH RAGA MEREK ADIDAS

(Studi di Kota Semarang)

(Rokh Eddy Prabowo; Kis Indriyaningrum; Anggita Dian Setyani - Universitas Stikubank Semarang) .121

PENGARUH KEMUDAHAN TERHADAP KEPUTUSAN MENGGUNAKAN E-BANKING PADA BNI 46 KC KARANGAYU SEMARANG DENGAN MINAT NASABAH DAN KEPERCAYAAN SEBAGAI VARIABEL MEDIASI

(Ahmad Sahri Romadon; Risma Nurhapsari - Universitas Semarang) 
PENELITIAN KEBERLANGSUNGAN USAHA ARDANI INDONESIA SEBAGAI UMKM BERBASIS INDUSTRI KREATIF

(Soegihartono - Universitas Semarang)

STRATEGI PELAYANAN BUS RAPID TRANSIT (BRT) TRANS SEMARANG

(Susanto - Universitas Semarang).....

ANALISIS PENGARUH KEPEMIMPINAN, STRES KERJA, DAN LINGKUNGAN KERJA TERHADAP KINERJA KARYAWAN BAGIAN PRODUKSI SEWING PT. SAMWON BUSANA INDONESIA SEMARANG

(Andana Budi Tami; Sri Yuni Widowati - Universitas Semarang). 


\title{
PENGARUH CITRA MEREK, PERSEPSI HARGA, DAN KUALITAS PRODUK TERHADAP KEPUTUSAN PEMBELIAN SEPATU OLAH RAGA MEREK ADIDAS (Studi di Kota Semarang)
}

\author{
Rokh Eddy Prabowo ${ }^{1}$ \\ Kis Indriyaningrum ${ }^{2}$ \\ Anggita Dian Setyani ${ }^{3}$ \\ eddybowo@edu.unisbank.ac.id ${ }^{1}$ \\ kis.indriyaningrum@edu.unisbank.ac.id ${ }^{2}$ \\ anggitadian95@gmail.com ${ }^{3}$
}

\section{Fakultas Ekonomika dan Bisnis Universitas Stikubank Semarang}

Diterima: Agustus 2020, Disetujui: September 2020, Dipublikasikan: Oktober 2020

\begin{abstract}
The purpose of the study is to analyze the effect of variables of: brand image, price perception and product quality to buying decision of Adidas brand shoes. The population is all buyers of the shoes in Semarang. The sample is 100 buyers by usingpurposive sampling. Primary data are derived from questionnaires distributed and secondary data are derived from library study. The data were analyzed with SPSS version 22. The results are: all indicators are valid and reliable. Coefficientdetermination test $\left(R^{2}\right)$ is $42,8 \%$. It means that the independent variables can explain dependent one amounted 42,8\%, meanwhile 57,2 \% is explained by other variables not discussed in the study. Test of $F$ indicated that model fit for the next analysis. Based on $t$ test, brand image did not affect buying decision significantly. While price perception and product quality significantly affect to buying decision of Adidas brand shoes in Semarang.
\end{abstract}

Keywords: Brand image, price perception, product quality, buying decision

ABSTRAK
Tujuan penelitian ini adalah untuk menganalisis pengaruh masing-masing variabel bebas: citra merek, persepsi harga, dan kualitas produk terhadap keputusan pembelian sepatu olah raga merek Adidas. Populasinya adalah semua pembeli sepatu olah raga merek Adidas di Semarang dan sampel ditetapkan sebanyak 100 pembeli dengan menggunakan teknik purposive sampling. Data primer diperoleh dengan menggunakan kuisioner dan data sekunder diperoleh dengan menggunakan studi pustaka. Data primer yang sudah dikumpulkan diolah dengan menggunakan SPSS versi 20. Hasil olahan SPSS adalah sbb.: Uji instrumen penelitian menunjukkan, bahwa semua indikator valid dan semua variabel reliabel. Uji Koefisien Determinasi $\left(\mathrm{R}^{2}\right)$ sebanyak 42,8 persen yang berarti, bahwa ketiga variabel bebas mampu mempengaruhi keputusan pembelian sepatu olah raga Adidas hanya 42,8 persen, sedangkan 57,2 persen dipengaruhi oleh variabel di luar penelitian ini. Walaupun demikian, namun hasil Uji Model F menunjukkan, bahwa model regresi layak digunakan sebagai model penelitian. 
Berdasarkan Uji t dan koefisien regresi menunjukkan, bahwa citra merek berpengaruh negatif dan tidak signifikan terhadap keputusan pembelian. Adapun persepsi harga dan kualitas produk masing-masing berpengaruh positif dan signifikan terhadap keputusan pembelian sepatu olah raga merek Adidas di Semarang.

Kata Kunci : Citra Merek, Persepsi Harga, Kualitas Produk, Keputusan Pembelian, Sepatu Adidas

\section{PENDAHULUAN}

Sepatu olah raga merek Adidas merupakan sepatu olah raga yang menarik untuk diteliti, karena data penjualan berdasarkan Top Brand Index Indonesia tahun 2017-2019 menempati ranking pertama, yaitu 38,2 persen (2017), 37,6 persen (22018), dan 37,0 persen (2019). Top Brand Index adalah bentuk apresiasi terhadap merek yang tergolong sebagai merek teratas. Top Brand Index ini didasarkan dari riset terhadap konsumen di Indonesia melalui tiga parameter yaitu top of mind share, top of market share, dan top of commitment share. Hasil Top Brand Index murni dari pilihan konsumen dan tidak ada campur tangan dari pihak lain.

Dalam penelitian ini memilih dan menetapkan tiga variabel bebas, yaitu: citra merek, persepsi harga, dan kualitas produk. Penetapan ketiga variabel ini berdasarkan dari beberapa penelitian dengan objek sepatu olah raga yang menunjukkan hasil yang berbeda (Research Gap). Hasil penelitian yang dimaksud ditunjukkan oleh: Andre Sanjaya dan Cut Irna Setyawati (2018), Hanna Meilana Damanik (2018), Raessa Adellina Dewi (2017), Rezza Nadia Putra dkk. (2017), Supriyadi dkk (2017), Abdul Samad dan Imam Wibowo (2016), Mutiara Widia Pradana Putri, dkk. (2016), Yugi Setyarko (2016), Annisa Ratih Kumala dan Penny Rahmawati (tanpa tahun), Aris Curigo (tanpa tahun), Nadwatul Haramaini dkk. (tanpa tahun), Nuki Dian Marchiati dkk (tanpa tahun), Ridwan Adji Baskoro (tanpa tahun), Sun Surya Fajri (tanpa tahun).

Menurut Abdul Samad dan Imam Wibowo (2016), Andre Sanjaya dan Cut Irna Setyawati (2018), Supriyadi dkk. (2017), Nuki Dian Marchiati dkk. (tanpa tahun), dan Ridwan Adji Baskoro (tanpa tahun) menyatakan, bahwa citra merek berpengaruh signifikan terhadap keputusan pembelian. Hasil penelitian ini berbeda dengan hasil penelitian: Raessa Adellina Dewi (2017), Mutiara Widia Pradana Putri, dkk. (2016), Nadwatul Haramaini dkk. (tanpa tahun), dan San Satya Safitri (tanpa tahun) yang menyatakan, bahwa citra merek tidak berpengaruh terhadap keputusan pembelian.

Pada variabel persepsi harga, manurut Hanna Meilana Damanik (2018), Raessa Adellina Dewi (2017), Annisa Ratih Kumala dan Penny Rahmawati (tanpa tahun), Aris Curigo (tanpa tahun), Nadwatul Haramaini dkk. (tanpa tahun), Ridwan Adji Baskoro (tanpa tahun), dan Sun Surya Fajri (tanpa tahun) menyatakan, bahwa persepsi harga berpengaruh signifikan terhadap keputusan pembelian. Berbeda dengan hasil penelitian Yugi Setyarko (2016) yang menyatakan, bahwa persepsi harga tidak berpengaruh terhadap keputusan pembelian.

Pada variabel kualitas produk, menurut Rezza Nadia Putra dkk (2017), Abdul Samad dan Imam Wibowo (2016), Nuki Dian Marchiati dkk (tanpa tahun), dan Ridwan Adji Baskoro (tanpa tahun) menemukan bukti, bahwa kualitas produk berpengaruh positif dan signifikan terhadap keputusan pembelian. Sementara menurut Hanna Meilana Damanik (2018), Supriyadi dkk (2017), dan Nadwatul Haramaini dkk. (tanpa 
tahun) menyatakan, bahwa bahwa kualitas produk berpengaruh negatif dan tidak signifikan terhadap keputusan pembelian.

Berdasarkan pada data empiris yang ditunjukkan oleh Top Brand Index dan Research Gap tersebut, maka penelitian ini akan menganalisis pengaruh citra merek, persepsi harga, dan kualitas produk dalam mempengaruhi keputusan pembelian sepatu olah raga merek Adidas (studi di Kota Semarang).

Ada tiga pertanyaan penelitian yang akan dicari jawabannya, yaitu:

a. Apakah citra merek berpengaruh posisif dan signifikan terhadap keputusan pembelian sepatu olah raga merek Adidas?

b. Apakah persepsi harga berpengaruh posisif dan signifikan terhadap keputusan pembelian sepatu olah raga merek Adidas?

c. Apakah kualitas produk berpengaruh posisif dan signifikan terhadap keputusan pembelian sepatu olah raga merek Adidas?

\section{TINJAUAN PUSTAKA}

Pada bagian ini akan menyajikan uraian tentang citra merek, persepsi harga, kualitas produk, dan keputusan pembelian. Uraian ini dimaksudkan untuk menyamakan persepsi, agar terdapat kesepahaman dalam memahami proses dan hasil penelitian ini. Uraian diawali dari citra merek, persepsi harga, kualitas produk, dan terakhir adalah keputusan pembelian.

Citra merek (Brand Image) menurut Kotler and Keller (2009) adalah sekumpulan persepsi dan kepercayaan yang dimiliki oleh pelanggan terhadap suatu brand yang direfleksikan melalui asosiasi-asosiasi yang ada dalam ingatan pelanggan. Dengan mengacu pada pendapat tersebut, maka merek yang sama untuk produk yang sama dari produsen yang sama dapat berbeda citra mereknya untuk konsumen yang berbeda. Jika suatu produk sudah memiliki citra yang baik dalam ingatan konsumen, maka konsumen akan dengan mudah melakukan keputusan pembelian terhadap produk yang diinginkan.

Pada sisi lain, apabila ingatan konsumen menyatakan citra merek suatu produk jelek, maka konsumen tidak mau untuk membeli produk yang bersangkutan. Dengan demikian citra merek dapat mempengaruhi konsumen dalam melakukan keputusan pembelian atau tidak membuat keputusan pembelian terhadap suatu produk. Keputusan membeli atau tidak membeli sangat tergantung pada persepsi yang ada di dalam ingatan konsumen. Ada lima indikator citra merek, yaitu: 1. Merek mudah diingat 2. Kualitas keseluruhan produk 3. Keterkenalan produk 4. Merek terpercaya 5. Merek memiliki tampilan yang menarik.

Persepsi harga adalah kecenderungan konsumen untuk menggunakan harga dalam memberi penilaian tentang kesesuaian manfaat produk. (Kotler dan Amstrong, 2008). Berdasarkan pada pengertian tersebut, maka dari satuan harga yang sama untuk produk yang sama bisa menimbulkan persepsi harga yang berbeda; ada yang mengatakan mahal dan ada yang mengatakan murah. Dikatakan mahal, apabila produk yang ditawarkan tidak memberikan manfaat yang diinginkan. Dikatakan murah, apabila produk yang ditawarkan memberi manfaat yang diinginkan. 
Dengan demikian secara teori persepsi harga dapat mempengaruhi konsumen untuk membeli atau tidak membeli suatu produk. Semakin murah persepsi harga menurut konsumen, maka semakin kuat konsumen membeli suatu produk tertentu. Di pihak lain, semakin mahal persepsi harga menurut konsumen, maka semakin tidak ada minat untuk membeli suatu produk. Ada empat indikator persepsi harga (Kotler dan Amstrong, 2008), yaitu: 1. Keterjangkauan harga 2. Kesesuaian harga dengan kualitas produk jasa 3. Daya saing harga 4. Kesesuaian harga dengan manfaat.

Kualitas produk (Kotler dan Keller, 2009) adalah interpretasi akumulasi berbagai informasi yang diterima konsumen. Dengan kata lain, kualitas produk dari sisi konsumen terjadi, karena hasil interpretasi konsumen atas informasi yang diperoleh. Ini dapat diartikan, bahwa apabila konsumen sudah berpendapat produk yang ditawarkan tidak sesuai dengan kualitas yang diingikan, maka susah untuk menerima pendapat dari produsen. Oleh karena itu, kualitas produk dapat mempengaruhi konsumen membeli atau tidak membeli suatu produk tertentu.

Menurut Kotler dan Keller (2009) ada sembilan dimensi informasi yang merupakan indikator untuk menentukan kualitas produk, yaitu: 1. Bentuk. 2. Fitur 3. Kualitas kinerja 4. Kesan kualitas 5. Ketahanan 6. Keandalan 7. Kemudahan perbaikan 8. Gaya 9. Desain. Kesembilan indikator ini berlaku untuk semua produk yang dipasarkan. Oleh karena itu, kesembilan indikator yang dimaksud juga dapat diberlakukan untuk dasar pembuatan instrument penelitian produk sepatu olah raga Adidas yang menjadi objek penelitian ini.

Keputusan pembelian adalah keputusan pembeli tentang merek mana yang dibeli. (Kotler dan Amstrong, 2008). Dengan kalimat lain, keputusan pembelian adalah perilaku konsumen pada saat menyerahkan sejumlah uang untuk mendapatkan sejumlah produk yang diinginkan. Dengan demikian konsumen benar-benar melakukan pembelian terhadap produk tertentu. Menurutnya ada lima indikator keputusan pembelian, yaitu : 1. Pilihan produk 2. Pilihan merek 3. Pilihan penyalur 4. Waktu pembelian 5. Jumlah pembelian.

\section{PENGEMBANGAN HIPOTESIS}

\section{Pengaruh Citra Merek terhadap KeputusanPembelian}

Berdasarkan pada pertanyaan penelitian, pengertian citra merek yang dikemukakan oleh Kotler and Keller (2009) dan hasil beberapa penelitian terdahulu yang dilakukan oleh Abdul Samad dan Imam Wibowo (2016), Andre Sanjaya dan Cut Irna Setyawati (2018), Supriyadi dkk. (2017), Nuki Dian Marchiati dkk. (tanpa tahun) yang menyatakan, bahwa citra merek berpengaruh positif dan signifikan terhadap keputusan pembelian, maka hipotesis dalam penelitian ini dirumuskan sbb.: $\mathrm{H}_{1}$ : Citra merek berpengaruh positif dan signifikan terhadap keputusan pembelian sepatu olah raga merek Adidas.

\section{Pengaruh Persepsi Harga terhadap Keputusan Pembelian}

Berdasarkan pada pertanyaan penelitian, definisi yang dikemukakan oleh Kotler dan Amstrong (2008) dan hasil penelitian Hanna Meilana Damanik (2018), Raessa Adellina Dewi (2017), Annisa Ratih Kumala dan Penny Rahmawati (tanpa tahun), Aris Curigo (tanpa tahun), Nadwatul Haramaini dkk. (tanpa tahun), Ridwan Adji Baskoro (tanpa tahun), Sun Surya Fajri (tanpa tahun) yang menyatakan, bahwa persepsi harga berpengaruh positif terhadap keputusan pembelian, maka hipotesis dalam penelitian ini dirumuskan sbb.: $\mathrm{H}_{2}$ : Persepsi harga 
berpengaruh positif dan signifikan terhadap Keputusan Pembelian sepatu olah raga merek Adidas.

\section{Pengaruh Kualitas Produk terhadap Keputusan Pembelian}

Berdasarkan pada pertanyaan penelitian, definisi kualitas produk yang dikemukakan oleh Kotler dan Keller (2009) dan hasil penelitian yang dihasilkan oleh Rezza Nadia Putra dkk (2017), Abdul Samad dan Imam Wibowo (2016), Nuki Dian Marchiati dkk (tanpa tahun), dan Ridwan Adji Baskoro (tanpa tahun) yang menyatakan, bahwa kualitas produk berpengaruh positif dan signifikan terhadap keputusan pembelian, maka hipotesis dalam penelitian ini dirumuskan sbb.: $\mathrm{H}_{3}$ : Kualitas produk berpengaruh positif dan signifikan terhadap Keputusan Pembelian sepatu olah raga merek Adidas.

\section{METODE PENELITIAN}

\section{Populasi, Sampel, dan Teknik Sampling}

Populasi dalam penelitian ini adalah semua konsumen yang membeli sepatu olah raga merek Adidas di Kota Semarang. Jumlah sampel ditentukan sebanyak 100 orang pembeli. Teknik sampling menggunakan purposive sampling.

\section{Jenis, Sumber, dan Teknik Pengambilan Data}

Jenis data primer diperoleh dari konsumen yang membeli sepatu olah raga merek Adidas dan teknik mendapatkan data dengan kuisioner. Adapun jenis data sekunder diperoleh dari Top Brand Index dengan teknik pustaka. Data primer yang sudah dikumpulkan diolah dengan bantuan Program SPSS versi 20.

\section{Model Penelitian}

a. Model Matematis

$$
\begin{aligned}
& \mathrm{Y}=\mathrm{a}+\mathrm{X}_{1}+\mathrm{X}_{2}+\mathrm{X}_{3}+\mathrm{e} \\
& \mathrm{Di} \text { mana: } \\
& \mathrm{Y}=\text { Keputusan pembelian } \\
& \mathrm{a}=\text { konstanta } \\
& \mathrm{X}_{1}=\text { Citra merek } \\
& \mathrm{X}_{2}=\text { Persepsi harga } \\
& \mathrm{X}_{3}=\text { Kualitas produk } \\
& \mathrm{e}=\text { eror }
\end{aligned}
$$

b. Model Grafis

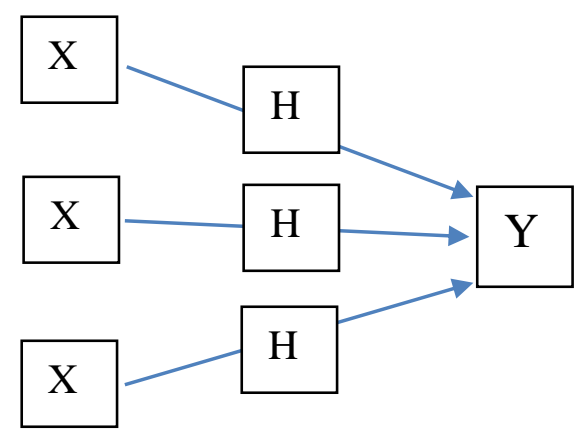




\section{Uji Istrumen}

\section{a. Uji Validitas}

Uji validitas pada penelitian ini menggunakan analisis faktor Kaiser MeyerOlkin Measure Of Sampling Adequacy (KMO). Apabila setiap pertanyaan pada indikator memiliki nilai loading of factor $>0,4$, maka pernyataan/pertanyaan dinyatakan valid. (Ghozali, 2018).

\section{b. Uji Reliabilitas}

Uji reliabilitas pada penelitian ini menggunakan Cronbach Alpha. Jika Cronbach Alpha > 0,7, maka kuisioner dikatakan konsisten atau reliabel. (Ghozali, 2018).

\section{Uji Statistik}

\section{a. Uji F (Uji Model)}

Uji F dilakukan untuk menentukan kelayakan model penelitian. Model digunakan untuk memprediksi perubahan variabel dependen (keputusan pembelian). Tingkat signifikansi Uji F ditetapkan 5 persen $(\alpha=0,05)$. Model dapat digunakan untuk memprediksi perubahan variabel dependen, apabila hasil SPSS versi 20 menunjukkan hasil kurang dari $<0,05$.

\section{b. Uji t (Uji Hipotesis)}

Uji t (Uji Hipotesis) dilakukan untuk menguji hipotesis yang sudah ditetapkan. Tingkat signifikansi dalam Uji Hipotesis ditetapkan 5 persen $(\alpha=0,05)$. Hipotesis diterima, apabila hasil SPSS versi 20 menunjukkan hasil kurang dari $<0,05$. Hipotesis ditolak, apabila hasil SPSS versi 20 menunjukkan hasil kurang dari >0,05.

\section{c. Uji Koefisien Determinasi $\left(\mathbf{R}^{2}\right)$}

Uji Koefisien Determinasi $\left(\mathrm{R}^{2}\right)$ digunakan untuk mengetahui persentase kemampuan tiga variabel bebas: citra merek, perspsi harga, dan kualitas produk dalam menjelaskan variabel terikat keputusan pembelian sepatu olah raga merek Adidas.

\section{HASIL DAN PEMBAHASAN}

\section{Deskripsi Responden}

Deskripsi responden dalam penelitian ini hanya pada tiga dimensi, yaitu: usia, jenis kelamin, dan tingkat pendidikan. Berdasarkan pada usia, yang paling banyak membeli sepatu olah raga mereka Adidas adalah mereka yang berusia 23-28 tahun (sebanyak 56 persen). Berdasarkan pada jenis kelamin, jenis kelamin laki-laki yang paling banyak membeli (sebanyak 70 persen). Dilihat dari tingkat pendidikan yang paling banyak membeli sepatu olah raga merek Adidas adalah Sarjana (sebanyak 50 persen).

Data ini mempunyai arti, bahwa segmen sepatu olah raga olah raga merek Adidas lebih banyak dibeli oleh orang laki-laki yang berusia antara 23-28 tahun dengan pendidikan Sarjana. Gambaran segmen pasar ini tidak berarti, bahwa perempuan kurang 
mendapat tempat untuk membeli sepatu olah raga merek Adidas. Jumlah perempuan yang membeli sepatu olah raga merek Adidas mencapai 44 persen. Perbandingan antara laki-laki dan perempuan yang membeli sepatu olah raga merek Adidas adalah 56 (lakilaki) : 44 (perempuan).

\section{Uji instrument}

\section{a. Uji Validitas}

Uji validitas menggunakan analisis faktor Kaiser Meyer-Olkin Measure Of Sampling Adequacy (KMO). Jika nilai loading of factor masing-masing pernyataan/pertanyaan indikator mempunyai nilai lebih dari $0,4 \quad(>0,4)$, maka pernyataan/pertanyaan indikator dinyatakan valid. Hasil olah data program SPSS versi 20 menunjukkan, bahwa semua pernyataan/pertanyaan indikator variabel citra merek, persepsi harga, kualitas produk, dan keputusan konsumen dinyatakan valid, karena seluruh variabel menunjukkan nilai $K M O$ berada pada kisaran 0,734 - 0,837. Hasil ini menjelaskan, bahwa jumlah sampel yang ditetapkan telah memenuhi syarat penelitian.

\section{b. Uji Reabilitas}

Uji reliabilitas berdasarkan hasil nilai Cronbach Alpha. Jika Cronbach Alpha > 0,7, maka kuisioner dikatakan konsisten atau reliabel. Berdasarkan pada hasil olah data program SPSS versi 20 nilai Cronbach Alpha masing-masing variabel penelitian, yaitu: citra merek $(0,793)$, persepsi harga $(0,809)$, kualitas produk $(0,872)$, dan keputusan pembelian $(0,736)$. Dengan demikian, maka masing-masing variabel telah memenuhi syarat untuk dikatakan reliabel.

\section{Uji Statistik}

\section{a. Uji F}

Berdasarkan hasil uji $\mathrm{F}$ diketahui angka signifikansi sebesar $0,000<\alpha=0,05$. Hal ini berarti bahwa variabel bebas kualitas produk, citra merek dan persepsi harga secara simultan berpengaruh terhadap keputusan pembelian sepatu olah raga merek Adidas, sehingga model regresi dalam penelitian ini dapat digunakan untuk memprediksi perubahan variabel dependen (keputusan pembelian).

\section{b. Uji Hipotesis (Uji t)}

Berdasarkan hasil perhitungan program SPSS versi 20 menunjukkan, bahwa pada tingkat signifikansi 5,00 persen $(\alpha=0,05)$ secara statistik citra merek berpengaruh negatif dan tidak signifikan terhadap keputusan pembelian sepatu olah raga merek Adidas, karena nilai signifikansinya $0,803>\alpha=0,05$. Adapun persepsi harga dan kualitas produk masing-masing berpengaruh positif dan signifikan terhadap keputusan pembelian sepatu olah raga merek Adidas, karena signifikansinya $=0,000<\alpha=0,05$. Hasil Uji t ini disajikan Tabel 3.1 yang memuat nilai koefosien regresi dan tingkat signifikasi hasil Uji t masing-masing variabel citra merek, persepsi harga, dan kualitas produk. 
Tabel 3.1 Hasil Regresi Variabel Citra Merek, Persepsi Harga, Kualitas Produk

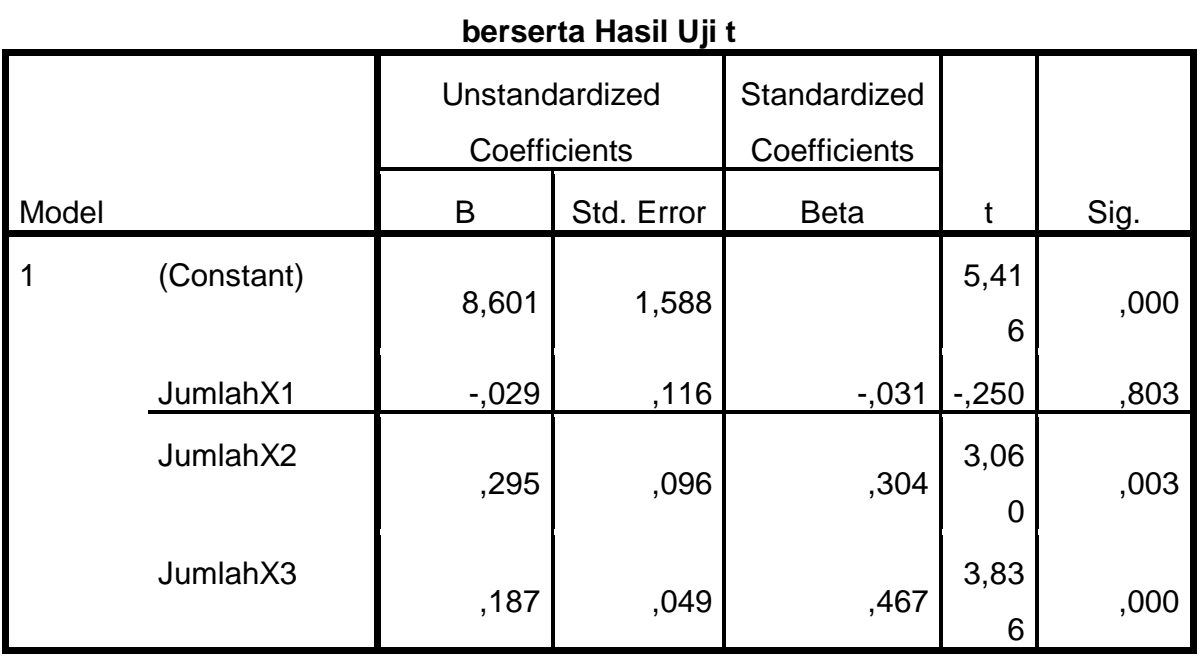

a. Dependent Variable: JumlahY

\section{Hasil Regresi Linier Berganda}

Berdasarkan Tabel 3.1 diperoleh persamaan regresi sebagai berikut:

$$
\mathrm{Y}=(-) 0,031 \mathrm{X}_{1}+0,304 \mathrm{X}_{2}+0,467 \mathrm{X}_{3}
$$

Hasil persamaan regresi linier berganda di atas dapat dijelaskan sebagai berikut:

1. Koefisien regresi citra merek $\left(X_{1}\right)$ bernilai negatif (-) 0,031. Secara statistik makin tinggi citra merek, maka makin turun jumlah penjualan. Apabila dihubungkan dengan objek penelitian ini, maka semakin tinggi citra merek sepatu olah raga merek Adidas, makin turun jumlah orang yang memutuskan untuk membeli sepatu olah raga merek Adidas. Pernyataan ini dikemukakan dengan asumsi, tidak ada perubahan pada variabel persepsi harga dan kualitas produk.

2. Koefisien regresi persepsi harga $X_{2}$ bernilai positif sebesar 0,304. Secara statistik ini berarti, bahwa makin baik persepsi harga sepatu olah raga merek Adidas, maka makin banyak orang yang membuat keputusan untuk membeli sepatu olah raga merek Adidas. Pernyataan ini dikemukakan dengan asumsi, tidak ada perubahan pada variabel citra merek dan kualitas produk.

3. Koefisien regresi kualitas produk $\left(\mathrm{X}_{3}\right)$ bernilai positif 0,467 . Secara statistik ini berarti, bahwa makin baik kualitas produk sepatu olah raga merek Adidas, maka makin banyak orang yang membuat keputusan untuk membeli sepatu olah raga merek Adidas. Pernyataan ini dikemukakan dengan asumsi, tidak ada perubahan pada variabel citra merek dan persepsi harga.

4. Berdasarkan pada nilai koefisien regresi, maka variabel kualitas produk $(0,467)$ yang paling kuat mempengaruhi keputusan pembelian sepatu olah raga merek Adidas. Peringkat kedua adalah varabel persepsi harga $(0,304)$ dan peringkat terakhir (peringkat ketiga) adalah variabel citra merek (-)0.031.

\section{Pembahasan}

Secara statistik tidak cukup bukti untuk menerima $\mathrm{H}_{1}$ : Citra merek berpengaruh positif dan signifikan terhadap keputusan pembelian sepatu olah raga merek Adidas. 
Berdasarkan pada Tabel 3.1 nampak, bahwa koefisien regresi citra merek negatif (-) 0,031 dan $\mathrm{t}$ hitung 0,803 (lebih besar dari tingkat signifikansi yang ditetapkan 0,5 persen). Hasil ini menunjukkan, bahwa citra merek berpengaruh negatif dan tidak signifikan terhadap keputusan pembelian sepatu olah raga merek Adidas.

Dalam beberapa penelitian, variabel bebas yang koefisien regresi negatif dan tidak signifikan dinyatakan, bahwa variabel bebas tersebut tidak berpengaruh terhadap variabel terikat. Dalam tulisan ini mengabaikan pernyataan yang demikian dan tetap dengan pernyataan citra merek berpengaruh negatif dan tidak signifikan terhadap keputusan pembelian sepatu olah raga merek Adidas. Dengan pernyataan ini berarti, bahwa secara statistik tidak cukup bukti untuk menyatakan citra merek berpengaruh negatif. Agar secara statistik signifikan, maka perlu dukungan data lagi untuk mendukung citra merek berpengaruh positif.

Apabila secara statistik tidak cukup bukti untuk menerima citra merek berpengaruh positif, maka bukan berarti dalam kenyataan citra merek benar-benar berpengaruh negatif. Untuk objek penelitian ini sulit untuk menerima pernyataan citra merek benar-benar berpengaruh negatif. Sedikitnya ada dua alasan, yaitu: Alasan pertama, posisi hasil penjualan sepatu olah raga merek Adidas yang dalam kurun waktu tiga tahun (2017-2019) menempati posisi nomer satu versi Top Brand Index. Salah satu variabel yang mempengaruhi adalah citra merek yang positif menurut konsumennya. Alasan kedua, out put program SPSS hanya berdasarkan pada data yang di in put untuk diolah. Bisa jadi, kalau data yang di in put kurang lengkap, sehingga hasilnya tidak mendukung untuk mendapatkan koefisien regresi yang positif. Satu hikmah yang perlu ditindaklanjuti adalah justru dengan temuan ini, maka penelitian-penelitian berikutnya tertantang untuk mengiventarisir indikator-indikator lain agar hasil SPSS saling mendukung.

Walaupun hasil penelitian ini menemukan, bahwa citra merek berpengaruh negatif dan tidak signifikan terhadap keputusan pembelian sepatu olah raga merek Adidas, namun mendapat dukungan dari hasil penelitian Raessa Adellina Dewi (2017), Mutiara Widia Pradana Putri, dkk. (2016), Nadwatul Haramaini dkk. (tanpa tahun), dan San Satya Safitri (tanpa tahun) yang menyatakan, bahwa citra merek berpengaruh negatif dan tidak signifikan terhadap keputusan pembelian sepatu olah raga merek Adidas.

Untuk persepsi harga hasil SPSS mempunyai cukup bukti untuk menerima persepsi harga berpengaruh positif dan signifikan terhadap keputusan pembelian sepatu olah raga merek Adidas. Dengan hasil seperti ini mempunyai makna, bahwa semakin banyak konsumen yang mempunyai persepsi harga sepatu olah raga merek Adidas murah, maka akan semakin banyak orang yang memutuskan untuk membeli sepatu olah raga merek Adidas. Secara statistik pernyataan ini dibenarkan, karena dinyatakan signifikan oleh hasil Uji t program SPSS.

Hasil ini menguatkan teori yang dikemukakan oleh Kotler dan Amstrong (2008) yang menyatakan, bahwa persepsi harga merupakan kecenderungan konsumen untuk menggunakan harga dalam memberi penilaian tentang kesesuaian manfaat produk. Apabila pernyataan ini dihubungkan data penjualan sepatu olah raga merek Adidas yang selama tiga tuhun berturut-turut (2017, 2018, dan 2019) menempati ranking pertama versi Top Brand Index, maka nampak harga sepatu olah raga merek Adidas sesuai 
dengan manfaat yang telah didapat oleh konsumennya. Menurut persepsi konsumen, harga sepatu olah raga merek Adidas masuk dalam kategori murah.

Hasil penelitian ini didukung oleh penelitian-penelitian terdahulu yang dilakukan oleh Hanna Meilana Damanik (2018), Raessa Adellina Dewi (2017), Annisa Ratih Kumala dan Penny Rahmawati (tanpa tahun), Aris Curigo (tanpa tahun), Nadwatul Haramaini dkk. (tanpa tahun), Ridwan Adji Baskoro (tanpa tahun), Sun Surya Fajri (tanpa tahun) yang menyatakan, bahwa persepsi harga berpengaruh signifikan terhadap keputusan pembelian.

Hasil SPSS yang berkaitan dengan regresi dan Uji t secara statistik mempunyai cukup bukti untuk menerima $\mathrm{H}_{3}$ yang berbunyi: kualitas produk berpengaruh positif dan signifikan terhadap keputusan pembelian sepatu olah raga merek Adidas. Hal ini mempunyai arti, bahwa hasil statistik mempunyai cukup bukti untuk menjustifikasi bahwa kualitas produk mampu meningkatkan jumlah konsumen untuk membeli sepatu olah raga merek Adidas. Dalam hal ini, makin bagus kualitas sepatu olah raga merek Adidas, maka makin bertambah orang untuk membeli sepatu olah raga merek Adidas.

Hasil ini menguatkan konsepsi kualitas produk yang dikemukakan oleh Kotler dan Keller (2009). Mereka mengatakan, bahwa kualitas produk adalah interpretasi akumulasi berbagai informasi yang diterima konsumen tentang suatu produk. Dengan kata lain, konsumenlah yang berpendapat bahwa produk yang ditawarkan berkualitas atau tidak berkualitas. Produsen hanya menyajikan produk beserta informasi pendukungnya. Oleh karena itu, kualitas produk dapat mempengaruhi konsumen membeli atau tidak membeli suatu produk tertentu.

Hasil penelitian ini mendapat dukungan dari para peneliti terdahulu, yaitu: Rezza Nadia Putra dkk. (2017), Abdul Samad dan Imam Wibowo (2016), Nuki Dian Marchiati dkk (tanpa tahun), dan Ridwan Adji Baskoro (tanpa tahun) yang menemukan bukti, bahwa kualitas produk berpengaruh positif dan signifikan terhadap keputusan pembelian.

Dari hasil keseluruhan dalam penelitian ini variabel yang memiliki pengaruh yang paling kuat terhadap keputusan pembelian adalah variabel kualitas produk $(0,467)$. Apabila dihubungkan dengan pernyataan di kuisioner, maka sepatu olah raga merek Adidas mampu memberikan hasil atau kinerja yang sesuai dan/atau bahkan melebihi dari apa yang diinginkan konsumen. Kondisi ini didukung oleh persepsi harga konsumen yang menyatakan, bahwa nominal harga yang ditetapkan oleh perusahaan sesuai dengan manfaat yang diperoleh konsumen atas sepatu olah raga merek Adidas yang dibelinya. Persepsi harga dengan nilai koefisien regresi $(0,304)$ menempati urutan kedua. Adapun variabel citra merek dengan nilai koefisien regresi negatif (-) 0,031 berada pada peringkat ketiga dalam mempengaruhi keputusan pembelian sepatu olah raga merek Adidas.

\section{SIMPULAN, KETERBATASAN, DAN SARAN}

\section{Simpulan}

Berdasarkan pada pertanyaan penelitian, hasil, dan pembahasan, maka penelitian ini menyimpulkan, bahwa:

1. Citra merek berpengaruh negatif dan tidak signifikan terhadap keputusan pembelian sepatu olah raga merek Adidas.

2. Persepsi harga berpengaruh positif dan signifikan terhadap keputusan pembelian sepatu olah raga merek Adidas. 
3. Kualitas produk berpengaruh positif dan signifikan terhadap keputusan pembelian sepatu olah raga merek Adidas.

\section{Keterbatasan}

Dalam penelitian ini secara statistik tidak mendapatkan cukup bukti untuk menerima hipotesis citra merek berpengaruh positif dan signifikan terhadap keputusan pembelian sepatu olah raga merek Adidas.

\section{Saran}

Saran untuk penelitian berikutnya a.l. menambah data-data yang secara statistik mempunyai cukup bukti untuk menerima pernyataan citra merek berpengaruh positif dan signifikan terhadap keputusan pembelian. Hal ini penting, karena secara konsep konsumen membeli suatu produk memperhatikan citra merek dari produk yang bersangkutan.

Saran untuk produsen sepatu olah raga merek Adidas, agar selalu meningkatkan citra merek dalam rangka mendukung kinerja pemasarannya.

\section{DAFTAR PUSTAKA}

Abdul Samad dan Imam Wibowo (2016). Pengaruh Produk dan Citra Merek terhadap Keputusan Pembelian Sepatu Olah RagaMerek Specs di Kota Bekasi. Jurnal Manajemen Bisnis Krisnadwipayana ISSN : 2338 - 4794 Vol. 4. No. 3 September 2016

Andre Sanjaya Siahaan dan Cut Irna Setiawati (2018). Pengaruh Citra Merek terhadap Keputusan Pembelian Sepatu Vans (Studi pada Mahasiswa Fakultas Komunikasi dan Bisnis Telkom University). e-Proceeding of Management : Vol.5, No.3 Dsember 2018 | Page 3813 ISSN : 2355-9357

Annisa Ratih Kumalasari dan Penny Rahmawati (tanpa tahun). Pengaruh Desain Produk, Persepsi Harga, dan Citra Merek terhadap Keputusan Pembelian Sepatu Basket Merek Nike pada Mahasiswa Anggota UKM Bola Basket seDIY (Studi Kasus pada Mahasiswa Anggota UKM Bola Basket se-DIY)

Aris Curigo (tanpa tahun). Pengaruh Inovasi Produk, Persepsi Harga dan Persepsi Kualitas terhadap Keputusan Pembelian Sepatu Sepak Bola Specs.

Ghozali, Imam. (2018). Aplikasi Analisis Multivariate dengan Progam IBM SPSS 22. Badan Penerbit Universitas Diponegoro. Semarang.

Hanna Meilani Damanik (2018). Pengaruh Kualitas Produk dan Harga terhadap Keputusan Pembelian Sepatu Casual Merek Bata. Jurnal Ilmiah Kohesi Vol. 2 No. 2 Mei 2018

Kotler dan Keller. (2009). Manajemen Pemasaran. Jilid I. Edisi ke 13. Jakarta. Erlangga.

Kotler dan Amstrong. (2008). Prinsip-prinsip Pemasaran. Jilid I dan 2. Edisi 12. Jakarta. Erlangga.

Mutiara Widia Pradana Putri dkk. (2016). Analisis Pengaruh Citra Merek, Kesadaran Merek, Persepsi Kualitas, dan Loyalitas Merek terhadap Keputusan Pembelian Sepatu Adidas (Survei pada Mahasiswa Universitas Slamet Riyadi Surakarta). Jurnal Ekonomi dan Kewirausahaan Vol. 16 No 2 Juni 2016: 234 - 241238 
Nadwatul Haramaini dkk. (tanpa tahun). Pengaruh Promosi, Harga, Citra Merek dan Kualitas Produk terhadap Keputusan Pembelian. e-Jurnal Riset Manajemen Prodi Manajemen Fakultas Ekonomi Unisma website : www.fe.unisma.ac.id (email : e.jrm.feunisma@gmail.com).

Nuki Dian Marchiani dkk. (tanpa tahun). Pengaruh Gaya Hidup, Citra Merek, dan Kualitas Produk terhadap Keputusan Pembelian Sepatu Sneakers Merek Converse (Studi pada Mahasiswa Universitas Diponegoro Semarang)

Raessa Adellina Dewi (tanpa tahun). Pengaruh Desain Produk, Harga dan Citra Merek terhadap Keputusan Pembelian Sepatu Merek Fladeo di Kota Padang.

Rezza Aulia Putra dkk (2017). Pengaruh Citra Merek Internasional (International Brand Image) dan Kualitas Produk terhadap Keputusan Pembelian (Survei pada Pembeli Sepatu Nike Running di Mall Olympic Garden Kota Malang). Jurnal Administrasi Bisnis (JAB) | Vol. 43 No.1 Februari 2017| administrasibisnis.studentjournal.ub.ac.id

Ridwan Adji Baskoro (tanpa tahun). Pengaruh Kualitas Produk, Harga, Promosi dan Citra Merek terhadap Keputusan Pembelian Sepatu Olah Raga Merek Adidas (Studi Kasus pada Mahasiswa Udinus Semarang)

San Surya Fajri (tanpa tahun). Analisis Pengaruh Citra Merek, Persepsi Harga, Desain dan Kualitas Produk terhadap Keputusan Pembelian Sepatu Futsal Merek "Nike" (Studi Kasus Toko Mukhlis Sport Klaten)

Supriyadi dkk (2017). Pengaruh Kualitas Produk dan Brand Image terhadap Keputusan Pembelian (Studi pada Mahasiswa Pengguna Produk Sepatu Merek Converse di FISIP Universitas Merdeka Malang). Jurnal Bisnis dan Manajemen Vol. 4 No.1, Januari 2017

https://www.topbrand-award.com/en/2017/07/sepatu-olahraga-fase-2-2017/

https://www.topbrand-award.com/en/2018/07/sepatu-olahraga-2018/

https://www.topbrand-award.com/en/2019/07/sepatu-olahraga-fase-2-2019/ 